\title{
Specialist treatment of chronic fatigue syndrome/ME: a cohort study among adult patients in England
}

\author{
Simon M Collin ${ }^{*}$ and Esther Crawley
}

\begin{abstract}
Background: NHS specialist chronic fatigue syndrome (CFS/ME) services in England treat approximately 8000 adult patients each year. Variation in therapy programmes and treatment outcomes across services has not been described.

Methods: We described treatments provided by 11 CFS/ME specialist services and we measured changes in patientreported fatigue (Chalder, Checklist Individual Strength), function (SF-36 physical subscale, Work \& Social Adjustment Scale), anxiety and depression (Hospital Anxiety \& Depression Scale), pain (visual analogue rating), sleep (Epworth, Jenkins), and overall health (Clinical Global Impression) 1 year after the start of treatment, plus questions about impact of CFS/ME on employment, education/training and domestic tasks/unpaid work. A subset of these outcome measures was collected from former patients $2-5$ years after assessment at 7 of the 11 specialist services.

Results: Baseline data at clinical assessment were available for 952 patients, of whom 440 (46.2\%) provided 1-year follow-up data. Treatment data were available for 435/440 (98.9\%) of these patients, of whom 175 (40.2\%) had been discharged at time of follow-up. Therapy programmes varied substantially in mode of delivery (individual or group) and number of sessions. Overall change in health 1 year after first attending specialist services was 'very much' or 'much better' for 27.5\% (115/418) of patients, 'a little better' for 36.6\% (153/418), 'no change' for 15.8\% (66/418), 'a little worse' for 12.2\% (51/418), and 'worse' or 'very much worse' for 7.9\% (33/418). Among former patients who provided 2to 5-year follow-up (30.4\% (385/1265)), these proportions were 30.4\% (117/385), 27.5\% (106/385), 11.4\% (44/385), 13.5\% (52/385), and 17.1\% (66/385), respectively. 85.4\% (327/383) of former patients responded "Yes" to "Do you think that you are still suffering from CFS/ME?" 8.9\% (34/383) were "Uncertain", and 5.7\% (22/383) responded "No".

Conclusions: This multi-centre NHS study has shown that, although one third of patients reported substantial overall improvement in their health, CFS/ME is a long term condition that persists for the majority of adult patients even after receiving specialist treatment.
\end{abstract}

Keywords: Chronic fatigue syndrome, ME, NHS England, Specialist care

\section{Background}

Chronic Fatigue Syndrome (CFS), also known as 'ME', is a long-term disabling condition characterised by debilitating fatigue of unknown cause, post-exertional malaise, cognitive dysfunction and disturbed/unrefreshing sleep, plus other symptoms including muscle and joint pain, headaches, and dizziness [1]. CFS/ME imposes an immense burden on patients, carers and families [2,3]. In the UK, adults who attend NHS specialist CFS/ME

\footnotetext{
* Correspondence: simon.collin@bristol.ac.uk

School of Social \& Community Medicine, Oakfield House, University of Bristol, Oakfield Grove, Bristol BS8 2BN, UK
}

(c) The Author(s). 2017 Open Access This article is distributed under the terms of the Creative Commons Attribution 4.0 International License (http://creativecommons.org/licenses/by/4.0/), which permits unrestricted use, distribution, and reproduction in any medium, provided you give appropriate credit to the original author(s) and the source, provide a link to the Creative Commons license, and indicate if changes were made. The Creative Commons Public Domain Dedication waiver (http://creativecommons.org/publicdomain/zero/1.0/) applies to the data made available in this article, unless otherwise stated. and half of those employed at the onset of their illness cease working [4]. A meta-analysis of CFS/ME prevalence studies based on clinically-confirmed cases in several countries gave a prevalence of $0.8 \%(95 \% \mathrm{CI}$ $0.2 \%$ to $1.3 \%$ ) [5].

Around 8000 patients are treated annually by NHS specialist CFS/ME services in England [6]. There are approximately 50 such services in England, many of which were established under the CFS/ME Service Investment Programme (2004-2006) [7]. These services follow guidance provided by the National Institute for 
Health \& Care Excellence (NICE), including specific guidelines for diagnosis, specialist care, and ongoing management, with an overall patient-centred approach to treatment [8].

In this study we used initial assessment and patientreported outcome data from newly referred and former patients who attended specialist CFS/ME services in England to investigate outcomes $1-5$ years after initial assessment by the service. We also collected patientlevel treatment data to describe variation in treatments across specialist services.

\section{Methods}

\section{Study cohort - newly referred patients}

Newly referred patients were recruited from 11 specialist CFS/ME services across England (10 NHS services, 1 registered independent provider) during the period 01/ $06 / 2014$ to $30 / 09 / 2016$. Patients were eligible if they were $\geq 18$ years old and had a CFS/ME diagnosis made or confirmed at an initial clinical assessment appointment in accordance with NICE guidelines [8].

\section{Patient-level data - newly referred patients}

At the time or their initial assessment, patients complete standard questionnaires to obtain quantitative measures of fatigue (Chalder Fatigue Scale [9] and Checklist Individual Strength (CIS20-R) [10]), physical function (RAND SF-36 [11]), general function (Work \& Social Adjustment Scale [12]), mood (Hospital Anxiety \& Depression Scale (HADS) [13]), pain (visual analogue pain rating scale), daytime sleepiness (Epworth Sleepiness Scale [14]), and sleep problems (Jenkins Sleep Scale [15]). Patients were also asked about the impact of ill health on employment, education/training, and unpaid work (e.g. housework, child care, voluntary work). The same set of questionnaires was sent to patients by post or via email (with a link to online versions of the questionnaires) approximately 12 months after their initial clinical assessment. At follow-up, patients were also asked to rate changes in overall health and CFS/ME (Clinical Global Impression scale), and were asked "Do you think that you are still suffering from CFS/ME?" Patients who didn't respond were contacted by the clinical team via phone or email on up to 2 further occasions to elicit a response. Data on treatment received by each patient were recorded by clinical teams or extracted from hospital administration databases at the end of the study. Treatment data included the date, duration and type of session (group or individual), and the qualification of the health care professional delivering the session.

\section{Study cohort - former patients}

For 7 of the 11 services, random samples of pseudonymous patient identifiers (50-60 per year for the period
2010-2013) were obtained from the CFS/ME National Outcomes Database (NOD). The CFS/ME NOD is a centralized repository of clinical assessment and patientreported outcome data which were routinely collected by NHS specialist CFS/ME services across England from 2006 to 2013 for the purpose of service evaluation. Lists of pseudonymous patient identifiers were sent to the clinical teams, who then sent out information sheets, consent forms and questionnaires to patients' home addresses.

\section{Patient-level data - former patients}

Patients who were treated by specialist services during the period 2010-2013 had already completed questionnaires to provide measures of fatigue (Chalder Fatigue Scale [9]) and physical function (RAND SF-36 [11]) when they were first assessed. At follow-up, former patients were sent these two questionnaires and were asked about changes in overall health and CFS/ME (Clinical Global Impression scale), and whether there had been any changes in employment, education/training, and their ability to do unpaid work/domestic tasks and social/leisure activities. They were also asked "Do you think that you are still suffering from CFS/ME?" Patient-level treatment data for former patients were not extracted from medical records.

\section{Statistical analysis}

Characteristics of patients who provided follow-up data were compared with patients who did not respond using the Chi-squared test for proportions and Kruskal-Wallis test for continuous measures (both $\alpha=0.05$ ). Changes (mean differences) in patient-reported measures between baseline (initial clinical assessment) and 1-year follow-up, and mean patient-reported measures at baseline and 1- to 5 -years follow-up were plotted with $95 \%$ confidence intervals. Evidence for associations between baseline comorbidities and overall change in health at 2- to 5-year was assessed using the Chi-squared test $(\alpha=0.05)$.

\section{Results \\ One-year follow-up of newly referred patients}

Of the 1067 newly referred patients recruited by the 11 services during the study period, 952 (89.2\%) had baseline data and were available for follow-up (Fig. 1). Of these patients, $771(81.0 \%)$ were female, the median (IQR) age was $41(30-50)$ years, and patients had been ill for 36 (15-84) months. Follow-up data were available for 440/ $952(46.2 \%)$ of patients, after an interval of 14.0 (12.516.7) months. Patients who responded tended to be older (42 (32-51) vs 39 (29-49) years, $p=0.003)$ and to have a shorter self-reported duration of illness $(26(12-80)$ vs 36 (18-84) months, $p=0.02$ ) (Additional file 1: Table S1). Common CFS/ME-related comorbidities tended to occur 


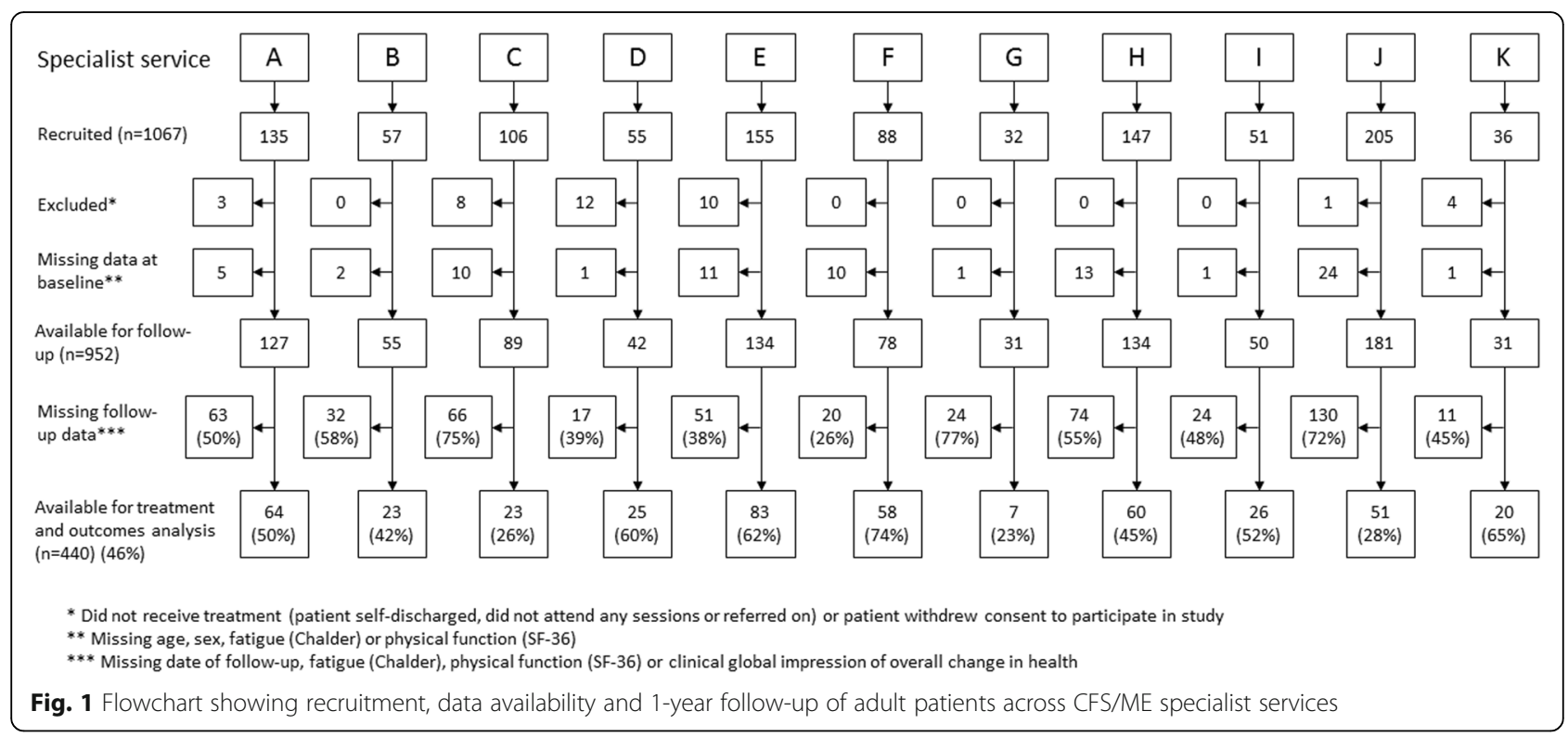

less frequently among responders vs non-responders: migraine $(20.1 \%(84 / 417)$ vs $26.6 \%(128 / 482), p=0.02)$, depression $(28.3 \%(115 / 406)$ vs $41.0 \%(194 / 473), p<0.001)$, and anxiety (32.4\% (132/407) vs $48.1 \%$ (229/476), $p<0.001)$. Conversely, at their initial assessment patients with follow-up were more likely to have been on sick leave (19.0\% (74/389) vs $12.8 \%(56 / 438), p=0.01)$ and had shorter working hours per week (21 (8-35) vs $25(10-37)$ hours, $p=0.06$ ). There were no differences between responders and non-responders in any other characteristics or measures.

Treatment data were available for $77.9 \%$ (742/952) of patients with baseline data, and for $98.9 \%$ (435/440) of patients with baseline and follow-up data (Table 1). Of patients who provided follow-up data, 40.2\% (175/435) did so after they had been discharged. The remaining $59.8 \%(260 / 435)$ had not yet completed treatment or had an open appointment or future follow-up appointment. Four services (D, E, F, and K) achieved $\geq 60 \%$ follow-up. Follow-up at the other services ranged from $23 \%$ to $52 \%$. One service $(G)$ had insufficient data $(n=7)$ for analysis of outcomes.

At 1 year after initial assessment, there was substantial variation in total duration of treatment sessions across services (Fig. 2, Table 1) and in the mix of individual and group sessions, type of health care professional delivery the session and/or content of the session (Additional file 1: Table S2). Median total duration of treatment sessions ranged from 19 to $20 \mathrm{~h}$ for services $\mathrm{C}$ and $\mathrm{K}$, to $4 \mathrm{~h}$ for services $\mathrm{D}$ and J. One service (D) provided only individual therapy sessions, two services (E and $\mathrm{G}$ ) provided mainly (>90\%) individual sessions, two services (C and I) mainly group therapy, and the remainder had ratios of individual: group therapy between 50:50 and 60:40. The median duration of therapy sessions was longer among patients with vs without follow-up data (8 (IQR 5-17) vs 6 (3-12), $p<0.001)$ and was shorter among patients who had been discharged vs patients who were still under treatment at the time of follow-up (6 (3-13) vs 9 (6-19), $p<0.001)$.

Changes (mean difference) in patient-reported measures between baseline and follow-up are shown in Fig. 3 and Table 2. There was evidence $(p<0.05)$ of reduction in fatigue on the Chalder Fatigue Scale across all services, with some variation in size of effect. Changes in other outcome measures tended to indicate beneficial effects of treatment, particularly in general function (Work and Social Adjustment Scale), depression, sleep (daytime sleepiness and sleep problems) and concentration and motivation (CIS20R). Evidence for improvements in physical function (SF36), pain, anxiety, and activity (CIS20R) was weaker and less consistent across the services.

Overall, 18\% (71/394) of patients reported returning to work or increasing working hours since first attending a specialist service, whilst 30\% (118/394) reported having ceased working or reduced hours because of CFS/ME and 47\% (186/394) reported no change (Table 3). Increased ability to perform unpaid work and domestic tasks was reported by $35 \%(129 / 372)$ of patients, reduced ability by $34 \%$ (127/372), and no change by $29 \%$ (109/ 372). Similarly, 35\% (139/397) of patients reported being able to do more social and leisure activities, 36\% (143/ $397)$ reported being less able, and $26 \%(102 / 397)$ reported no change. Only 5\% (11/240) reported returning to, or increasing hours of education/training, whilst $13 \%$ $(31 / 240)$ ceased or reduced their hours and 79\% (189/ 240) reported no change. 


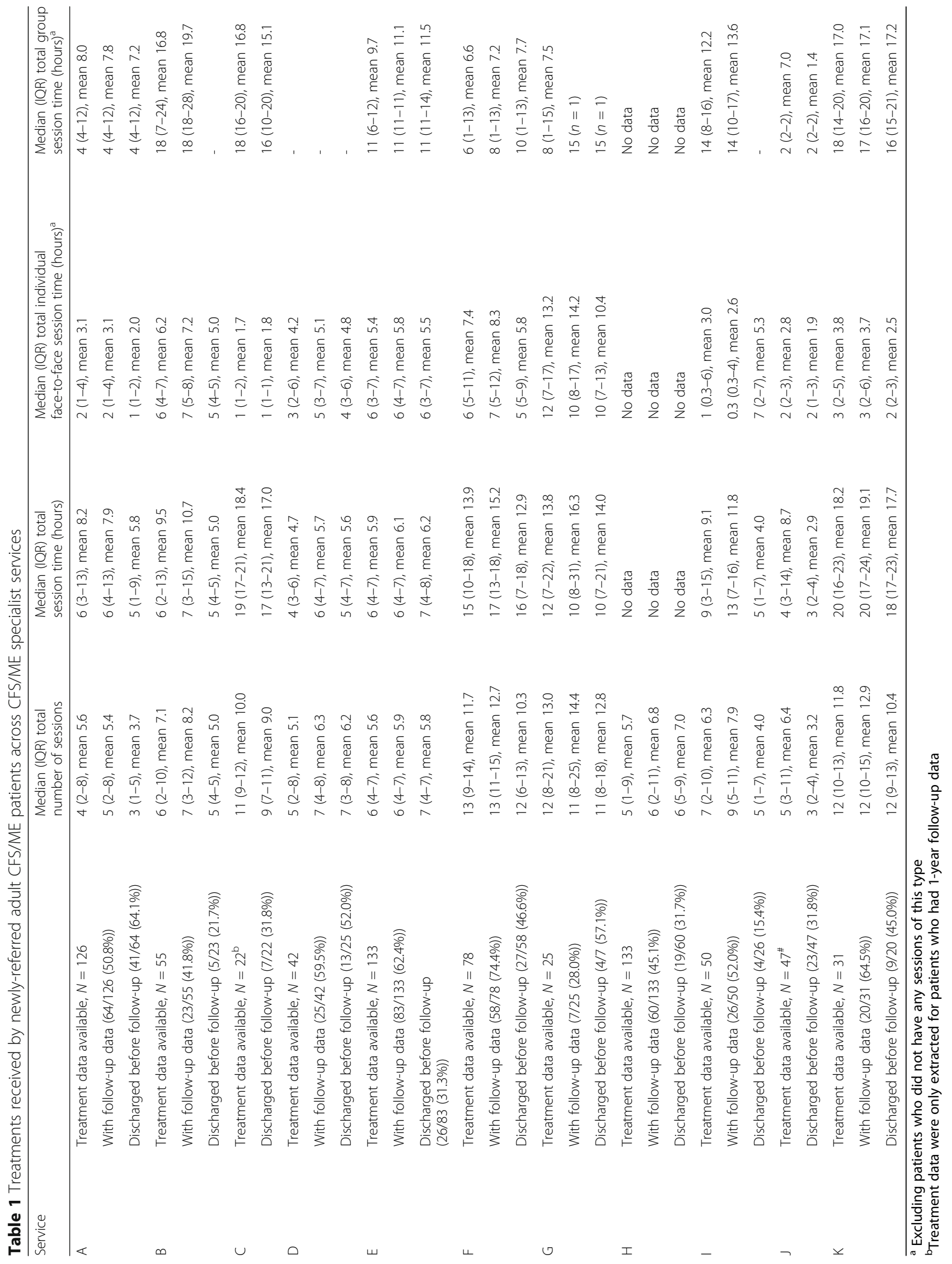




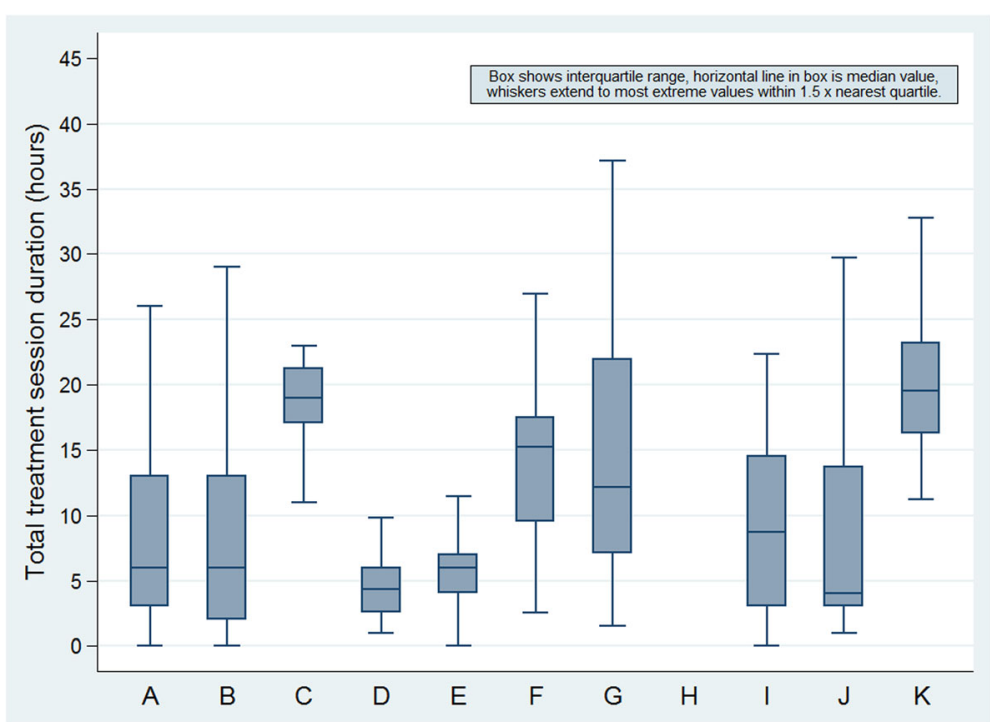

Fig. 2 Box chart showing total duration of all treatment sessions (individual face-to-face, individual telephone/internet or group) across CFS/ME specialist services
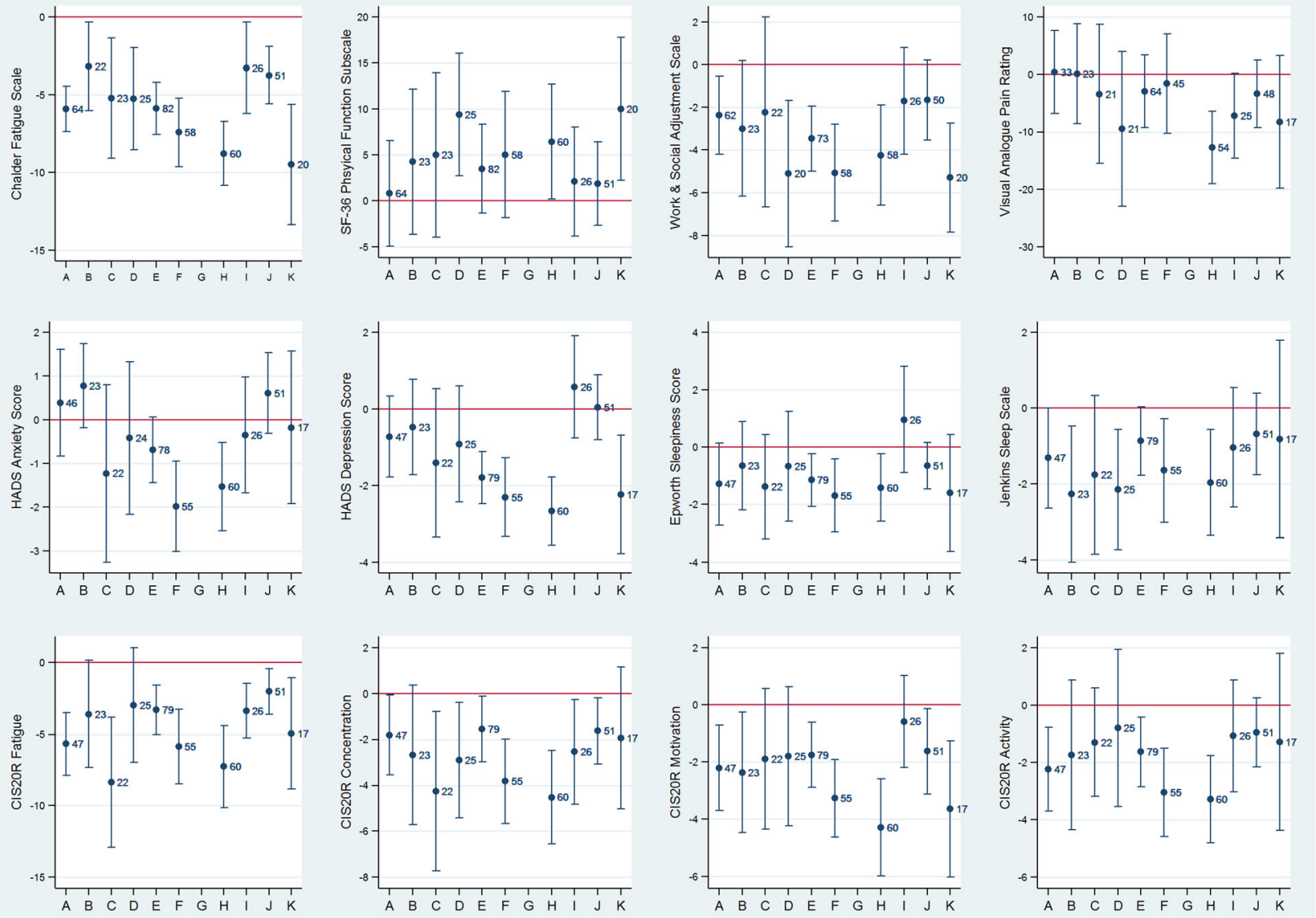

Fig. 3 Changes (mean difference with 95\% Cl) in patient reported outcome measures between initial assessment and 1-year follow-up across CFS/ME specialist services 


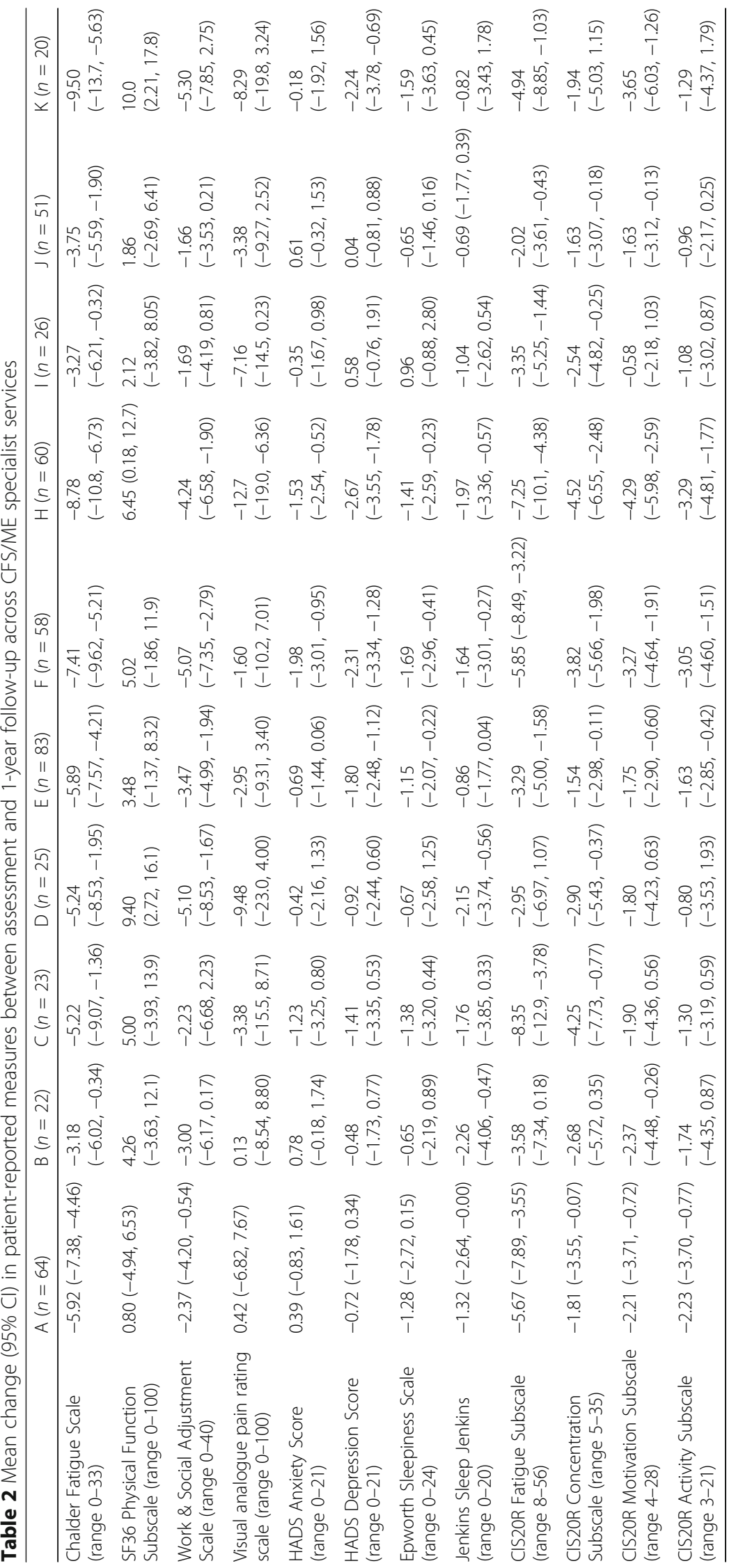




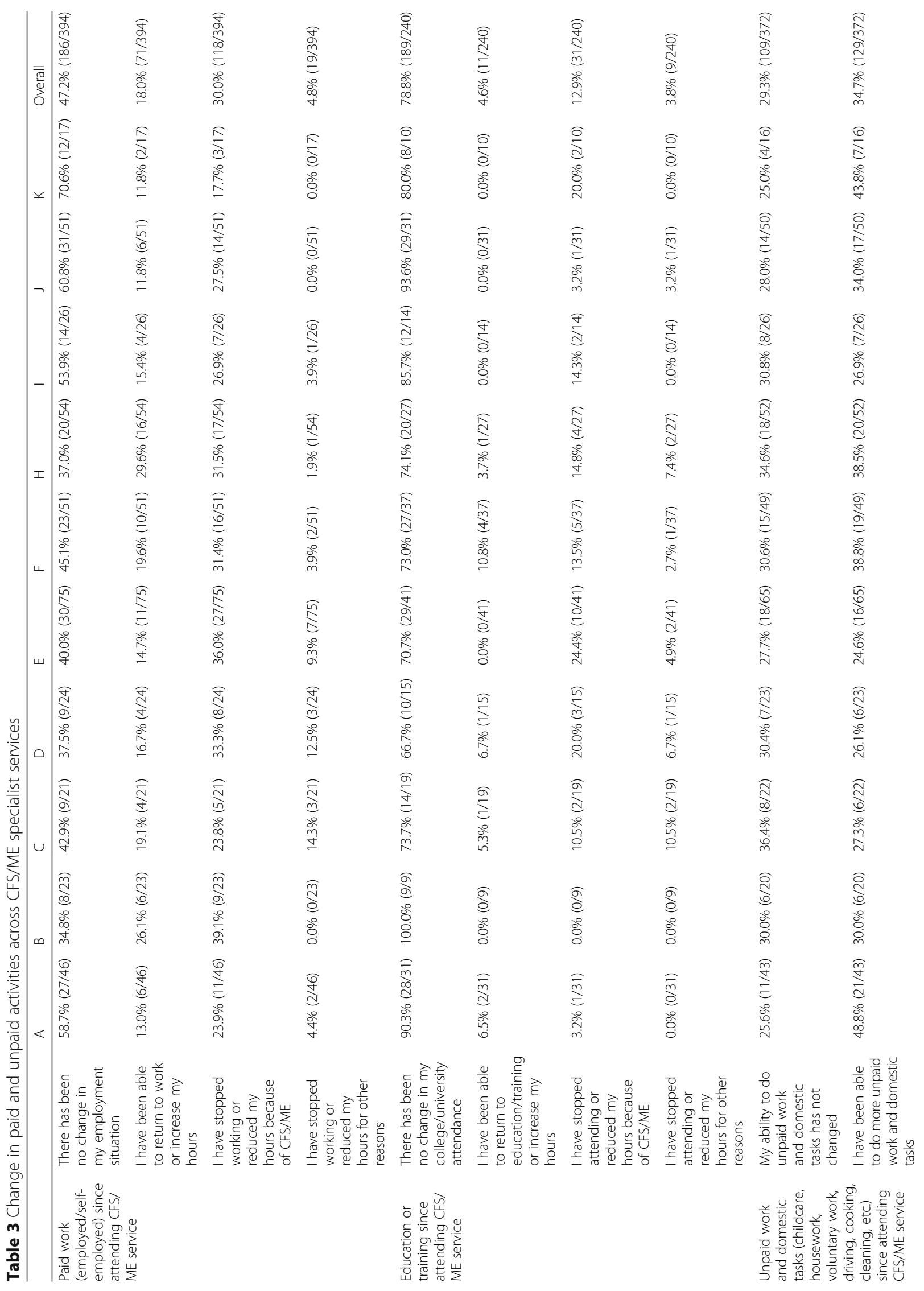




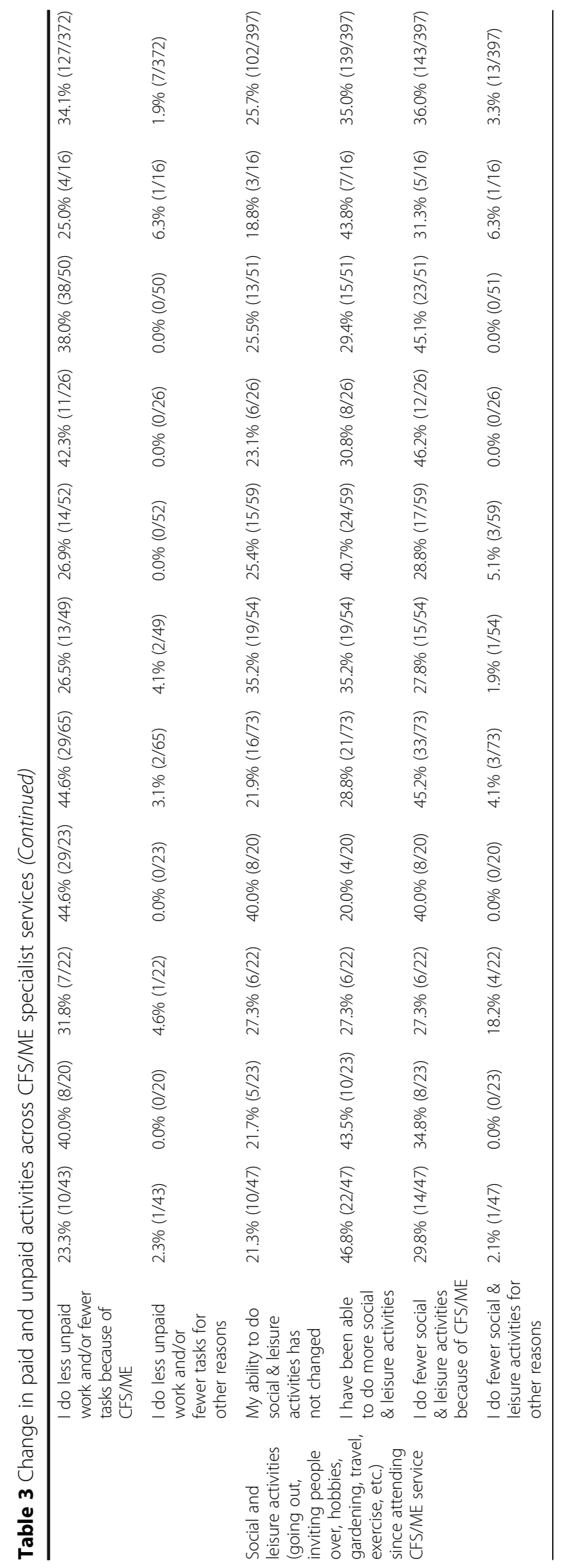


Overall changes in health were reasonably consistent across the specialist services, with $28 \%(115 / 418)$ reporting their health as much better or very much better, 65\% (270/418) reporting little or no change, and $8 \%(33 / 418)$ reporting much worse or very much worse health (Table 4, Fig. 4). Of those reporting little or no change, the majority said that they were 'a little better' (36.6\% (153/418)), with $15.8 \%(66 / 418)$ indicating 'no change' and $12.2 \%(51 / 418)$ a slight deterioration. Similar proportions were observed in response to the question "Overall, how much do you feel your CFS/ME has changed since you first came to the service?" In response to the question "Do you think that you are still suffering from CFS/ME?" 87\% (341/391) responded "Yes", 3\% (11/391) "No" and 10\% (39/391) were "Uncertain". Of those who responded "Yes", 23\% (78/339) also said that their overall health was much or very much better, compared with $82 \%$ (9/11) of those who responded "No" and 58\% (21/36) of those who were "Uncertain". Changes (mean difference) in patient-reported measures between baseline and follow-up for each level of overall improvement in health are provided as supplementary information (Additional file 2: Figure S1 and Additional file 1: Table S3).

\section{Long-term (2- to 5-year) follow-up of former patients}

Seven of the specialist services attempted to contact random samples of former patients who were assessed and treated in 2010, 2011, 2012 or 2013 (total $N=1265$ ), and long-term follow-up questionnaires were returned by $30 \%(385 / 1265)$ of these patients (Fig. 5). Baseline characteristics (at time of assessment) were the same in patients who did vs did not respond, except that patients who responded tended to be older $(43(33-51)$ vs 38 (30-47) years, $p<0.001)$ (Additional file 1: Table S4), and less likely to have presented with comorbid depression $(26.6 \%(89 / 335)$ vs $34.8 \%$ (247/709), $p=0.008)$. Otherwise, there were no differences between responders and non-responders in any other baseline characteristics or measures. There was no difference between the two groups in their responses to the Clinical Global Impression question "Overall, how much do you feel your health has changed since you first came to the CFS/ME service?" at 1 year follow-up, with 32\% (84/263) of non-responders vs $38 \%(84 / 223)$ of responders indicating that they were very much or much better, $58 \%$ $(153 / 263)$ vs $56 \%(124 / 223)$ reporting little or no change, and $10 \%(26 / 263)$ vs $7 \%(15 / 223)$ indicating that they were very much or much worse $(p=0.26)$.

Patient-reported measures of fatigue and physical function showed no overall change from 1 year followup onwards (Table 5, Fig. 6), but stratification by responses to the Clinical Global Impression questionnaire at 2 to 5 years post-assessment showed that $30-40 \%$ of patients improved from 1 year onwards, $40-60 \%$ experienced little or no change, and $20-25 \%$ deteriorated (Fig. 6). Over the 2-5 year follow-up period, 24\% (88/ 372) of former patients reported being able to return to work or increase their working hours, 12\% (29/238) returned to, or increased their hours of, education, 36\% $(132 / 365)$ increased unpaid work and domestic tasks, and 35\% (133/382) increased their social and leisure activities (Table 6). Conversely, 27\% (102/372), 13\% (29/238), $32 \%(117 / 365)$, and $39 \%(149 / 382)$ reported stopping or reducing paid work, education/training, unpaid/domestic work, and social/leisure activities, respectively.]

Approximately half of former patients (52.5\% (202/385)) reported little or no overall change in their health (of whom half said that they were a little better), one third (30.4\% (117/385)) said that they were very much or much better, and $17 \%(66 / 385)$ rated their health as very much or much worse. The majority of former patients $(85 \%$ (327/383)) responded affirmatively to the question "Do you think that you are still suffering from CFS/ME?", 6\% (22/383) said "No", and 9\% (34/383) were "Uncertain". Of those who responded "Yes", 23\% (74/327) also said that their overall health was much or very much better, compared with 95\% (21/22) of those who responded "No" and $62 \%(21 / 34)$ of those who were "Uncertain".

Overall change in health at 2- to 5-year follow-up was associated with comorbid fibromyalgia $(p=0.005)$ and depression $(p=0.02)$ recorded at the patient's baseline clinical assessment, but was not associated with comorbid anxiety, migraine, or irritable bowel syndrome. Very much or much better health was reported by $15.7 \%(13 / 83)$ vs $34.4 \%$ $(86 / 250)$ of patients who did vs did not have comorbid fibromyalgia, and by $22.5 \%(20 / 89)$ vs $32.1 \%$ (79/246) of patients with vs without comorbid depression. Very much or much worse health was reported by $21.7 \%$ $(18 / 83)$ vs $14.8 \%(37 / 250)$ of patients with vs without fibromyalgia, and by $25.8 \%(23 / 89)$ vs $13.4 \%$ (33/246) of patients with vs without comorbid depression.

\section{Discussion}

This study has described substantial variation in total therapy time for adult patients attending NHS specialist CFS/ME services in England. Changes in patientreported outcome measures approximately one year after patients' initial assessments demonstrated clear improvement, particularly in fatigue, general function, depression, sleep, concentration, and motivation. At one year follow-up, one quarter of patients rated their overall health as very much or much better, the majority (two thirds) reported little or no change (of whom half had improved slightly), and $<10 \%$ reported much or very much worse health. Just under $90 \%$ of patients said that they were still suffering from CFS/ME, although one quarter of these also said that their overall health was 


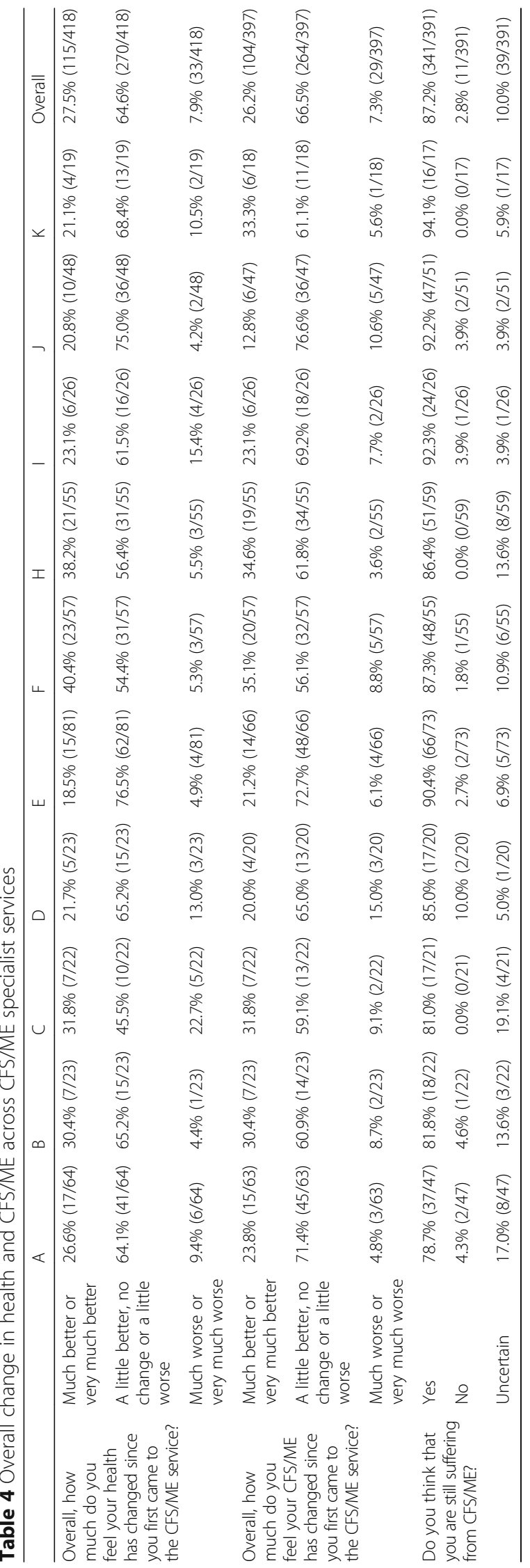




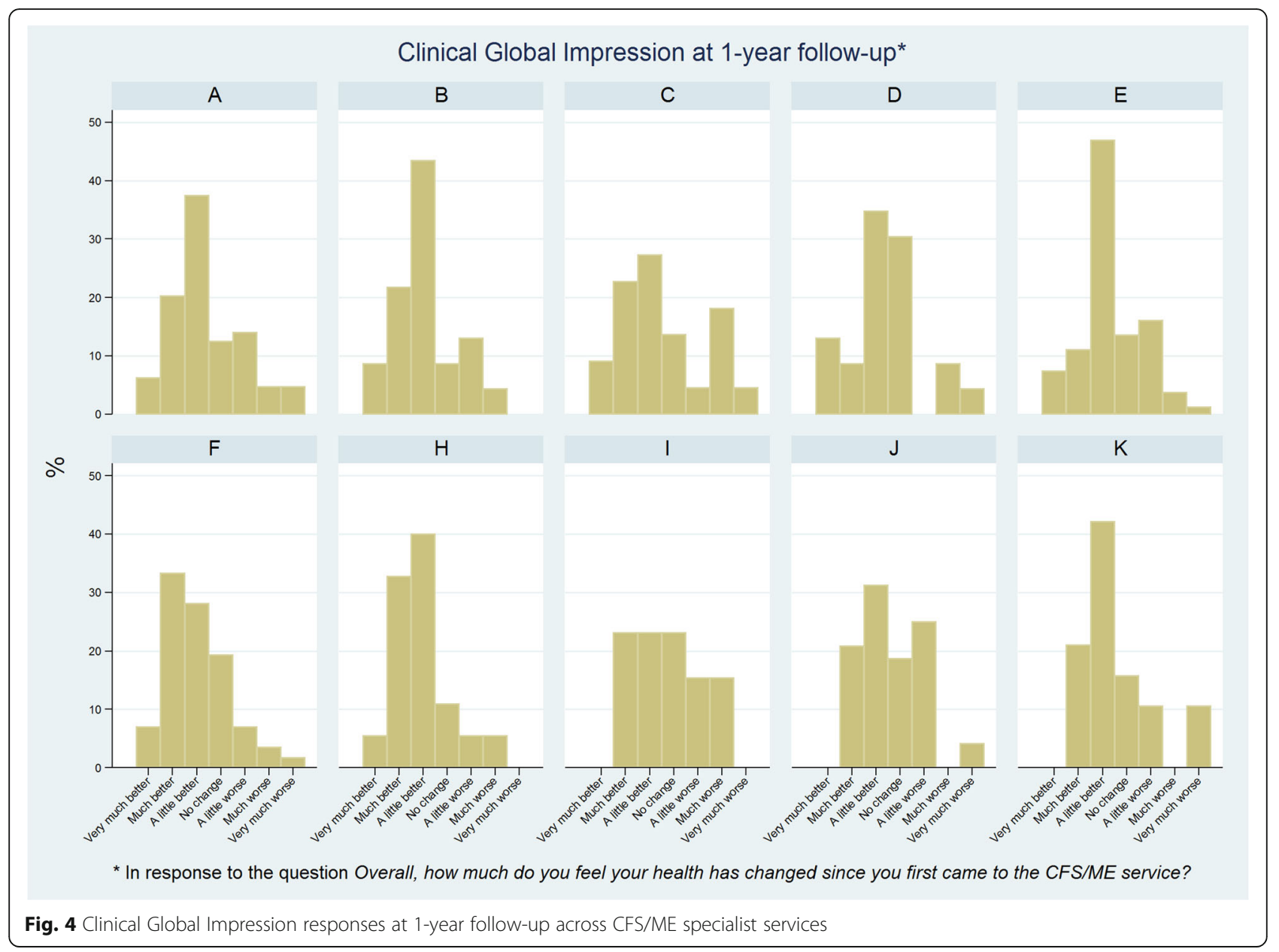

very much or much better. Among former patients who returned long term (2- to 5-year) follow-up questionnaires, one third rated their overall health as very much or much better, half reported little or no change, $17 \%$ reported substantial deterioration, and $85 \%$ said that they were still suffering from CFS/ME.

\section{Strengths and limitations}

The main strength of our study is that a large cohort of patients was recruited from NHS specialist services in England, all of which follow NICE guidelines for the diagnosis and management of CFS/ME [8]. This should ensure that the patients in our study have been diagnosed with CFS/ME according to the same criteria, namely persistent or recurrent debilitating fatigue of $\geq 4$ months' duration which is not lifelong, or the result of ongoing exertion, or alleviated by rest, or explained by other conditions, and which results in a substantial reduction in activity. We measured patient-reported outcomes using standardised questionnaires which are used routinely in clinical practice, and which have also been used widely in epidemiological research $[16,17]$.
The main limitation of this study is the substantial loss to follow-up, both among the newly referred patients and among the former patients. Although 12-month follow-up of newly referred patients was $74 \%$ at one service and $60-65 \%$ at three services, follow-up at the other seven services ranged from 23 to $52 \%$. Long-term follow-up of former patients was $30 \%$. These losses to follow-up mean that all of our analyses must be interpreted with the caveat that bias could be introduced in either direction if patients who were more (or less) likely to recover were more (or less) likely to return their questionnaires. Another limitation is that we measured outcomes in newly-referred patients at a fixed time after their initial assessment, with $60 \%$ of patients still being under treatment at time of follow-up. Also, measurement of outcomes at a single time point is not ideal for an illness which can fluctuate over time.

\section{Comparison with previous literature}

The best comparators for our real world results are the results reported by the PACE trial of cognitive behaviour therapy (CBT) and graded exercise therapy (GET) for adults with CFS/ME. The PACE trial showed a reduction 


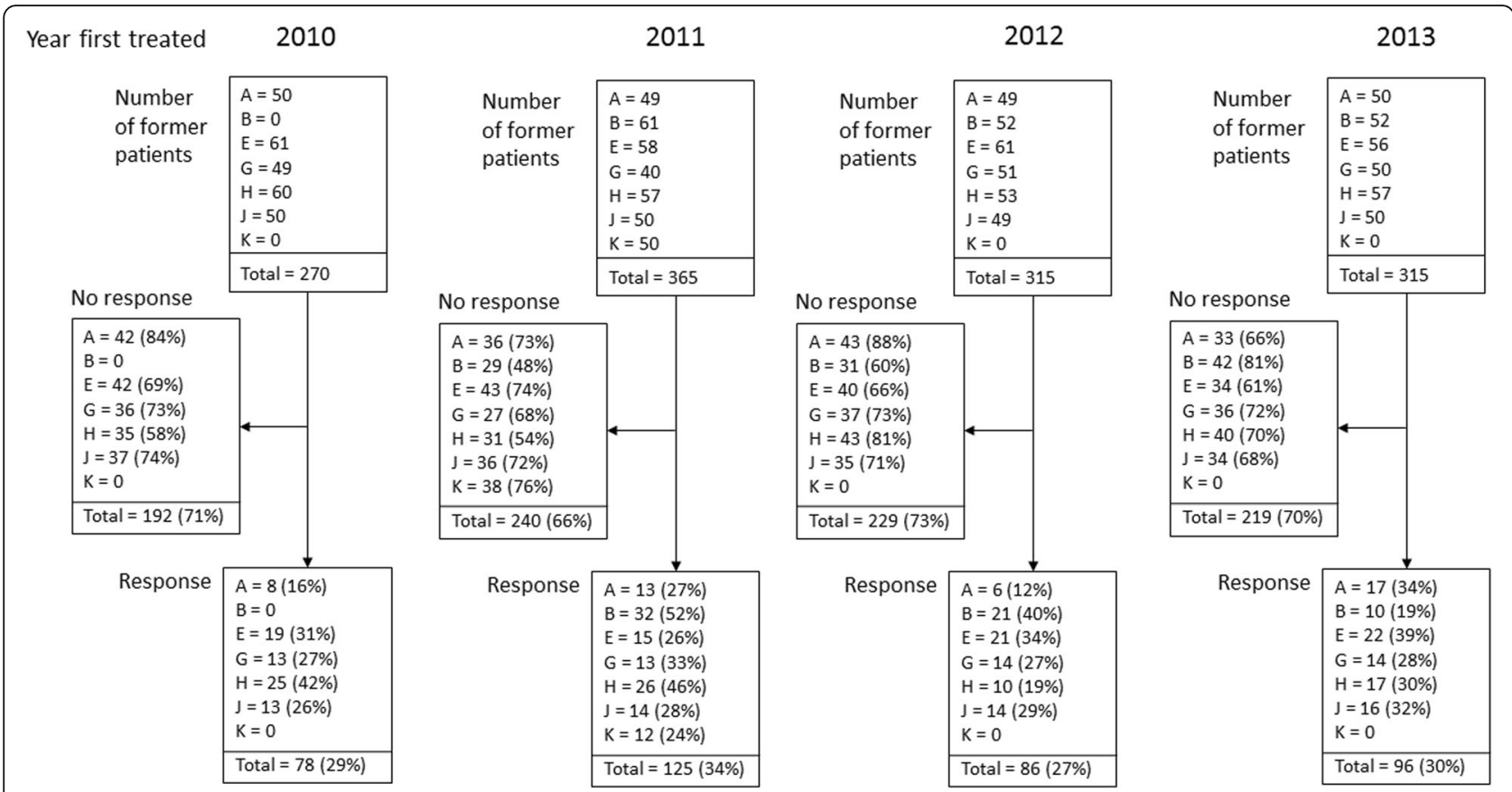

Fig. 5 Flowchart showing follow-up of former patients treated 2-5 years previously by CFS/ME specialist services

(in the CBT and GET arms) in mean fatigue (on the Chalder Scale) from 28 points at randomisation to 20 points at 12 months [18], followed by a slight (1-2 point) further reduction at 31 (IQR 30-32) months follow-up [19]. This is very similar to the trend observed in our data. PACE reported larger improvements in physical function (from 37 to 39 points at baseline to 58 points at 12 months followed by slight or no further change at long-term follow-up) than observed in our study, a difference between trial and real world outcomes which we found previously in an analysis of routinelycollected data [20]. The proportions of PACE trial participants (in the CBT and GET arms) who rated their overall health as very much or much better at 12 and 31 months were $41 \%$ and $42-48 \%$, respectively, compared with $28 \%$ and $30 \%$ in our study (at 12 months and $2-5$ years).

We cannot say whether these differences represent better long term outcomes attributable to the treatment programmes in the trial, the effect of the majority of patients in our study still being under treatment, or bias in our study if patients who improved were more likely to be lost to follow up. Participants in the CBT and GET arms of the PACE trial received (median (IQR)) 14 (12-15) individual CBT sessions ( $86 \%$ face-to-face, $14 \%$ by telephone) and 13 (12-14) individual GET sessions (94\% faceto-face, $6 \%$ by telephone) respectively, and one fifth went on to receive further therapy sessions after the trial ended. Only four services in our study (C, F, G, and $\mathrm{K}$ ) provided a similar number of therapy sessions, with considerable variation in follow-up and outcomes. One of these services (F) provided $12(6-13)$ therapy sessions and follow-up was obtained from $74 \%$ (58/78) of patients of whom $40 \%$ $(23 / 57)$ rated their overall health as very much or much better. In this service, the ratio of individual: group therapy was 50:50, which suggests scope for even better cost-effectiveness than reported in the PACE trial [21].

\section{Implications for clinical practice and future research}

Pointers for future research are perhaps given by some of the between-service differences in outcomes. For example, patients who were treated by service D (with $60 \%$ follow-up) reported particularly good improvements in physical function despite receiving a relatively small number (median 7 (IQR 3-8)) of (mostly GET) sessions - this service also delivered $28 \%$ of therapy sessions via telephone. Service K (with 65\% follow-up) obtained similar improvements in physical function by means of a larger number of sessions (12 (9-13), mostly with an occupational therapist) of which $65 \%$ were group sessions. These similarities in outcomes and differences in modes of delivery merit further exploration, and could form the basis of future randomised controlled trials. Similarly, treatments in our study were delivered by multidisciplinary teams variously comprising specialist clinicians, clinical psychologists, occupational therapists, and physiotherapists, which highlights the lack of an evidence base regarding the optimal mix of health care professionals required to deliver the most cost-effective service. Factorial trials are particularly suited to addressing multiple questions about content and delivery of treatments [22], 
Table 5 Median (IQR) fatigue and physical function at baseline (assessment) and at 1- to 5-year follow-up among patients treated by CFS/ME specialist services

\begin{tabular}{|c|c|c|c|c|c|c|c|}
\hline & & Baseline & 1 year & 2 years & 3 years & 4 years & 5 years \\
\hline \multirow[t]{4}{*}{$\begin{array}{l}\text { Chalder Fatigue } \\
\text { Scale (range 0-33) }\end{array}$} & All former patients in sample & $\begin{array}{l}28(24-31) \\
n=1265\end{array}$ & $\begin{array}{l}21(13-26) \\
n=516\end{array}$ & $\begin{array}{l}20(15-27) \\
n=80\end{array}$ & $\begin{array}{l}21(15-26) \\
n=83\end{array}$ & $\begin{array}{l}20(16-26) \\
n=106\end{array}$ & $\begin{array}{l}21(14-28), \\
n=99\end{array}$ \\
\hline & $\begin{array}{l}\text { Patients who reported very } \\
\text { much or much better overall } \\
\text { health at } 2,3,4 \text {, or } 5 \text { years }\end{array}$ & $\begin{array}{l}27(23-40) \\
n=117\end{array}$ & $\begin{array}{l}16(11-22) \\
n=69\end{array}$ & $\begin{array}{l}15.5(11-20) \\
n=20\end{array}$ & $\begin{array}{l}14(8-19) \\
n=22\end{array}$ & $\begin{array}{l}16(11-19) \\
n=41\end{array}$ & $\begin{array}{l}11(11-17) \\
n=31\end{array}$ \\
\hline & $\begin{array}{l}\text { Patients who reported little } \\
\text { or no change in overall } \\
\text { health at } 2,3,4 \text {, or } 5 \text { years }\end{array}$ & $\begin{array}{l}27.5(23-30) \\
n=202\end{array}$ & $\begin{array}{l}22(16-26) \\
n=124\end{array}$ & $\begin{array}{l}20.5(15.5-27) \\
n=52\end{array}$ & $\begin{array}{l}22(18-26) \\
n=47\end{array}$ & $\begin{array}{l}21(17-24) \\
n=47\end{array}$ & $\begin{array}{l}21(19-27) \\
n=43\end{array}$ \\
\hline & $\begin{array}{l}\text { Patients who reported very } \\
\text { much or much worse overall } \\
\text { health at } 2,3,4 \text {, or } 5 \text { years }\end{array}$ & $\begin{array}{l}27(33-66) \\
n=30\end{array}$ & $\begin{array}{l}24.5(19-32) \\
n=42\end{array}$ & $\begin{array}{l}30(24-32) \\
n=8\end{array}$ & $\begin{array}{l}33(26-33) \\
n=14\end{array}$ & $\begin{array}{l}30.5(26-33) \\
n=18\end{array}$ & $\begin{array}{l}31(25-33) \\
n=25\end{array}$ \\
\hline \multirow[t]{4}{*}{$\begin{array}{l}\text { SF36 Physical Function } \\
\text { Subscale (range 0-100) }\end{array}$} & All former patients in sample & $\begin{array}{l}47(27-67) \\
n=1265\end{array}$ & $\begin{array}{l}52(32-77) \\
n=516\end{array}$ & $\begin{array}{l}52(29.5-74.5) \\
n=80\end{array}$ & $\begin{array}{l}52(27-77) \\
n=83\end{array}$ & $\begin{array}{l}57(32-82) \\
n=106\end{array}$ & $\begin{array}{l}52(32-82) \\
n=99\end{array}$ \\
\hline & $\begin{array}{l}\text { Patients who reported very } \\
\text { much or much better overall } \\
\text { health at } 2,3,4 \text {, or } 5 \text { years }\end{array}$ & $\begin{array}{l}52(37-67) \\
n=117\end{array}$ & $\begin{array}{l}72(52-82) \\
n=69\end{array}$ & $\begin{array}{l}77(49.5-97) \\
n=20\end{array}$ & $\begin{array}{l}87(67-97) \\
n=22\end{array}$ & $\begin{array}{l}82(62-87) \\
n=41\end{array}$ & $\begin{array}{l}87(72-97) \\
n=31\end{array}$ \\
\hline & $\begin{array}{l}\text { Patients who reported little } \\
\text { or no change in overall } \\
\text { health at } 2,3,4 \text {, or } 5 \text { years }\end{array}$ & $\begin{array}{l}47(32-62) \\
n=202\end{array}$ & $\begin{array}{l}49.5(32-72) \\
n=124\end{array}$ & $\begin{array}{l}52(29.5-72) \\
n=52\end{array}$ & $\begin{array}{l}47(27-67) \\
n=47\end{array}$ & $\begin{array}{l}52(27-67) \\
n=47\end{array}$ & $\begin{array}{l}52(32-72), \\
n=43\end{array}$ \\
\hline & $\begin{array}{l}\text { Patients who reported very } \\
\text { much or much worse overall } \\
\text { health at } 2,3,4 \text {, or } 5 \text { years }\end{array}$ & $\begin{array}{l}29.5(17-52) \\
n=66\end{array}$ & $\begin{array}{l}24.5(12-52) \\
n=42\end{array}$ & $\begin{array}{l}24.5(7-34.5) \\
n=8\end{array}$ & $\begin{array}{l}17(2-37) \\
n=14\end{array}$ & $\begin{array}{l}22(7-47) \\
n=18\end{array}$ & $\begin{array}{l}22(2-37) \\
n=25\end{array}$ \\
\hline
\end{tabular}
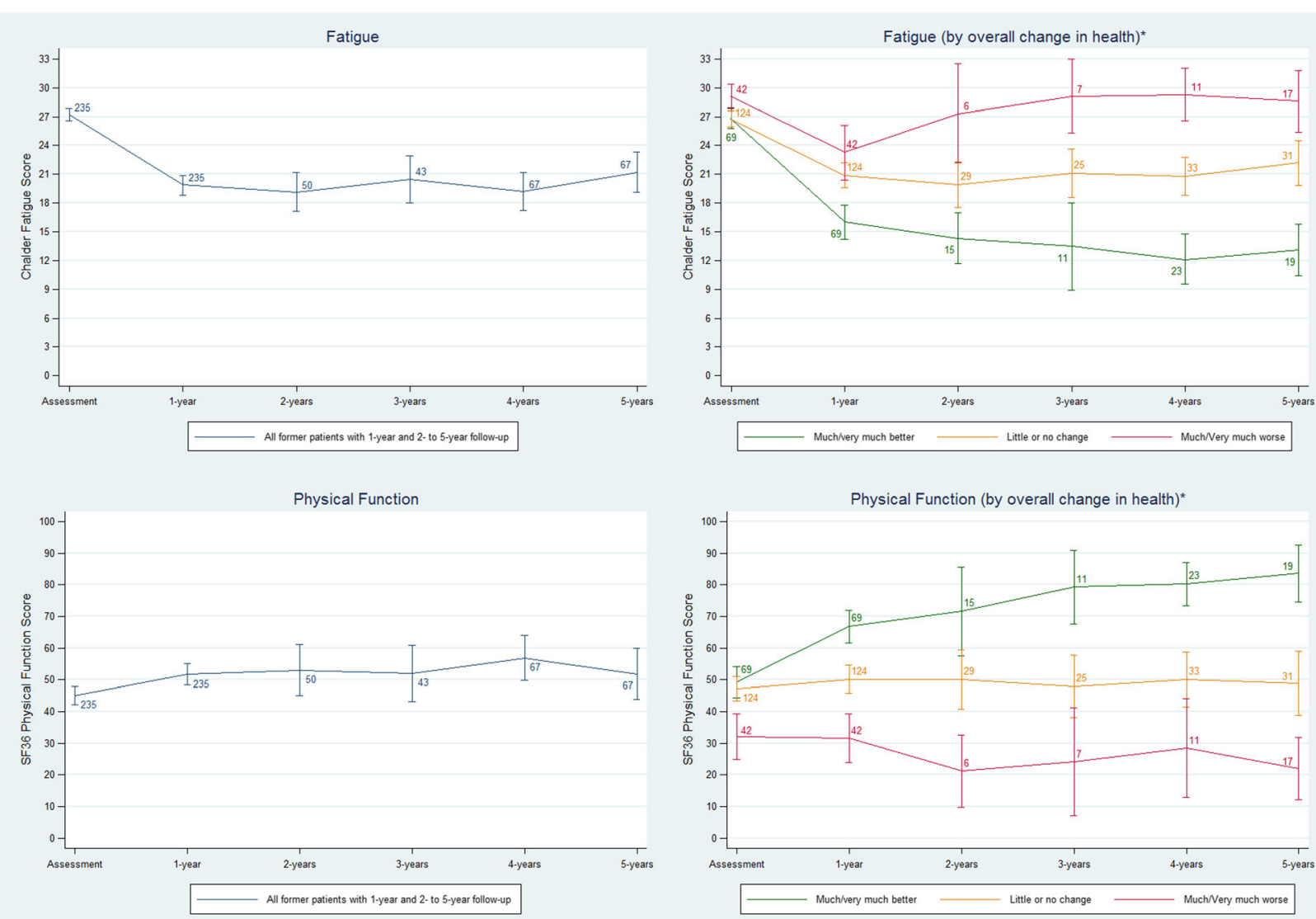

*In response to the question Overall, how much do you feel your health has changed since you first came to the CFS/ME service? asked at 2- to 5-year follow-up

Fig. 6 Trends in patient-reported fatigue (Chalder) and physical function (SF36) from initial assessment up to 5 years follow-up among patients treated by CFS/ME specialist services 
Table 6 Change in activities and health across CFS/ME specialist services at 2- to 5-year follow-up

\begin{tabular}{|c|c|c|c|c|c|c|}
\hline & & 2 years & 3 years & 4 years & 5 years & Overall \\
\hline \multirow{4}{*}{$\begin{array}{l}\text { Paid work (employed/self- } \\
\text { employed) since attending } \\
\text { CFS/ME service }\end{array}$} & $\begin{array}{l}\text { There has been no change } \\
\text { in my employment situation }\end{array}$ & $51.3 \%(39 / 76)$ & $45.0 \%(36 / 80)$ & $41.8 \%(43 / 103)$ & $26.8 \%(26 / 97)$ & $41.4 \%(154 / 372)$ \\
\hline & $\begin{array}{l}\text { I have been able to return } \\
\text { to work or increase my hours }\end{array}$ & $18.4 \%(14 / 76)$ & $17.5 \%(14 / 80)$ & $28.2 \%(29 / 103)$ & $30.9 \%(30 / 97)$ & 23.7\% (88/372) \\
\hline & $\begin{array}{l}\text { I have stopped working or } \\
\text { reduced my hours because } \\
\text { of CFS/ME }\end{array}$ & $26.3 \%(20 / 76)$ & $28.8 \%(23 / 80)$ & $22.3 \%(23 / 103)$ & $32.0 \%(31 / 97)$ & $27.4 \%(102 / 372)$ \\
\hline & $\begin{array}{l}\text { I have stopped working or } \\
\text { reduced my hours for other } \\
\text { reasons }\end{array}$ & $4.0 \%(3 / 76)$ & $8.8 \%(7 / 80)$ & $7.8 \%(8 / 103)$ & $10.3 \%(10 / 97)$ & $7.5 \%(28 / 372)$ \\
\hline \multirow[t]{4}{*}{$\begin{array}{l}\text { Education or training since } \\
\text { attending CFS/ME service }\end{array}$} & $\begin{array}{l}\text { There has been no change } \\
\text { in my college/university } \\
\text { attendance }\end{array}$ & $57.8 \%(26 / 45)$ & $69.0 \%(40 / 58)$ & $69.2 \%(45 / 65)$ & $74.1 \%(43 / 58)$ & $67.7 \%(161 / 238)$ \\
\hline & $\begin{array}{l}\text { I have been able to return to } \\
\text { education/training or increase } \\
\text { my hours }\end{array}$ & $11.1 \%(5 / 45)$ & $10.3 \%(6 / 58)$ & $15.4 \%(10 / 65)$ & $10.3 \%(6 / 58)$ & $12.2 \%(29 / 238)$ \\
\hline & $\begin{array}{l}\text { I have stopped attending or } \\
\text { reduced my hours because of } \\
\text { CFS/ME }\end{array}$ & $17.8 \%(8 / 45)$ & $17.2 \%(10 / 58)$ & $7.7 \%(5 / 65)$ & $8.6 \%(5 / 58)$ & $12.6 \%(30 / 238)$ \\
\hline & $\begin{array}{l}\text { I have stopped attending or } \\
\text { reduced my hours for other } \\
\text { reasons }\end{array}$ & $13.3 \%(6 / 45)$ & $3.5 \%(2 / 58)$ & $7.7 \%(5 / 65)$ & $6.9 \%(4 / 58)$ & $7.6 \%(18 / 238)$ \\
\hline \multirow{4}{*}{$\begin{array}{l}\text { Unpaid work and domestic } \\
\text { tasks (childcare, housework, } \\
\text { voluntary work, driving, cooking, } \\
\text { cleaning, etc.) since attending } \\
\text { CFS/ME service }\end{array}$} & $\begin{array}{l}\text { My ability to do unpaid work } \\
\text { and domestic tasks has not } \\
\text { changed }\end{array}$ & $26.3 \%(20 / 76)$ & $31.3 \%(25 / 80)$ & $24.8 \%(25 / 101)$ & $30.1 \%(28 / 93)$ & $29.3 \%(107 / 365)$ \\
\hline & $\begin{array}{l}\text { I have been able to do more } \\
\text { unpaid work and domestic tasks }\end{array}$ & $29.0 \%(22 / 76)$ & $33.8 \%(27 / 80)$ & $42.6 \%(43 / 101)$ & $38.7 \%(36 / 93)$ & $36.2 \%(132 / 365)$ \\
\hline & $\begin{array}{l}\text { I do less unpaid work and/or } \\
\text { fewer tasks because of CFS/ME }\end{array}$ & $39.5 \%(30 / 76)$ & $35.0 \%(28 / 80)$ & $30.7 \%(31 / 101)$ & $28.0 \%(26 / 93)$ & $32.1 \%(117 / 365)$ \\
\hline & $\begin{array}{l}\text { I do less unpaid work and/or } \\
\text { fewer tasks for other reasons }\end{array}$ & $5.3 \%(4 / 76)$ & $0.0 \%(0 / 80)$ & $2.0 \%(2 / 101)$ & $3.2 \%(3 / 93)$ & $2.5 \%(9 / 365)$ \\
\hline \multirow{4}{*}{$\begin{array}{l}\text { Social and leisure activities } \\
\text { (going out, inviting people } \\
\text { over, hobbies, gardening, } \\
\text { travel, exercise, etc.) since } \\
\text { attending CFS/ME service }\end{array}$} & $\begin{array}{l}\text { My ability to do social \& leisure } \\
\text { activities has not changed }\end{array}$ & $25.0 \%(20 / 80)$ & $34.6 \%(28 / 81)$ & $14.2 \%(15 / 106)$ & $22.5 \%(22 / 98)$ & $23.0 \%(88 / 382)$ \\
\hline & $\begin{array}{l}\text { I have been able to do more } \\
\text { social \& leisure activities }\end{array}$ & $28.8 \%(23 / 80)$ & $32.1 \%(26 / 81)$ & $37.7 \%(40 / 106)$ & $37.8 \%(37 / 98)$ & $34.8 \%(133 / 382)$ \\
\hline & $\begin{array}{l}\text { I do fewer social \& leisure } \\
\text { activities because of CFS/ME }\end{array}$ & $43.8 \%(35 / 80)$ & $32.1 \%(26 / 81)$ & $43.4 \%(46 / 106)$ & $35.7 \%(35 / 98)$ & $39.0 \%(149 / 382)$ \\
\hline & $\begin{array}{l}\text { I do fewer social \& leisure activities } \\
\text { for other reasons }\end{array}$ & $2.5 \%(2 / 80)$ & $1.2 \%(1 / 81)$ & $4.7 \%(5 / 106)$ & $4.1 \%(4 / 98)$ & $3.1 \%(12 / 382)$ \\
\hline \multirow{3}{*}{$\begin{array}{l}\text { Overall, how much do you feel } \\
\text { your health has changed since } \\
\text { you first came to the CFS/ME } \\
\text { service? }\end{array}$} & Much better or very much better & $25.0 \%(20 / 80)$ & $26.5 \%(22 / 83)$ & $38.7 \%(41 / 106)$ & $31.3 \%(31 / 99)$ & $30.4 \%(117 / 385)$ \\
\hline & $\begin{array}{l}\text { A little better, no change or a } \\
\text { little worse }\end{array}$ & $65.0 \%(52 / 80)$ & $56.6 \%(47 / 83)$ & $44.3 \%(47 / 106)$ & $43.4 \%(43 / 99)$ & $52.5 \%(202 / 385)$ \\
\hline & Much worse or very much worse & $10.0 \%(8 / 80)$ & $16.9 \%(14 / 83)$ & $17.0 \%(18 / 106)$ & $25.3 \%(25 / 99)$ & $17.1 \%(66 / 385)$ \\
\hline \multirow{3}{*}{$\begin{array}{l}\text { Overall, how much do you feel } \\
\text { your CFS/ME has changed since } \\
\text { you first came to the CFS/ME } \\
\text { service? }\end{array}$} & Much better or very much better & $18.8 \%(15 / 80)$ & $28.9 \%(24 / 83)$ & $41.0 \%(43 / 105)$ & $35.1 \%(34 / 97)$ & $31.4 \%(120 / 382)$ \\
\hline & $\begin{array}{l}\text { A little better, no change or a } \\
\text { little worse }\end{array}$ & $73.8 \%(59 / 80)$ & $57.8 \%(48 / 83)$ & $41.0 \%(43 / 105)$ & $43.3 \%(42 / 97)$ & $53.1 \%(203 / 382)$ \\
\hline & Much worse or very much worse & $7.5 \%(6 / 80)$ & $13.3 \%(11 / 83)$ & $18.1 \%(19 / 105)$ & $21.7 \%(21 / 97)$ & $15.5 \%(59 / 382)$ \\
\hline \multirow{3}{*}{$\begin{array}{l}\text { Do you think that you are } \\
\text { still suffering from CFS/ME? }\end{array}$} & Yes & $86.3 \%(69 / 80)$ & $90.4 \%(75 / 83)$ & $82.1 \%(87 / 106)$ & $82.7 \%(81 / 98)$ & $85.4 \%(327 / 383)$ \\
\hline & No & $5.0 \%(4 / 80)$ & $2.4 \%(2 / 83)$ & $6.6 \%(7 / 106)$ & $8.2 \%(8 / 98)$ & $5.7 \%(22 / 383)$ \\
\hline & Uncertain & $8.8 \%(7 / 80)$ & $7.2 \%(6 / 83)$ & $11.3 \%(12 / 106)$ & $9.2 \%(9 / 98)$ & $8.9 \%(34 / 383)$ \\
\hline
\end{tabular}

and these could also be designed (by randomising predefined subgroups of patients with specific comorbidities and/or symptom profiles) to investigate the big question in
CFS/ME treatment, namely why some patients experience substantial improvement whilst others report little or no improvement. 
Qualitative research has shown that specialist CFS/ME services play an important role in patients' journeys towards improved quality of life [23, 24]. Anecdotally, services report overall high patient satisfaction, which may appear to be at odds with a minority of patients experiencing substantial improvement. This apparent paradox may be explained in part by the difficulty of measuring long-term outcomes in a complex chronic illness $[16,25]$, a problem which could perhaps be addressed by using objective rather than subjective measures [26]. We might also consider how outcomes in our study compare with other chronic illnesses, such as chronic widespread pain, fibromyalgia, arthritis and multiple sclerosis $[22,27,28]$, and with the poor prognosis for CFS/ME in adults if no specialist treatment is received. Our qualitative study was set in three of the eleven services in the present study [23]. It showed that referral to a CFS/ME specialist service was typically the first positive step in coming to terms with a life changing contested illness, with improvement coming about through a process which included validation of patients' experiences, acceptance of change, practical advice and support, and therapeutic outcomes. Professional support was an important theme, and we recognize that some of the between-service differences in outcomes in the present study may be attributable to therapist effects [29-31].

\section{Conclusions}

This multi-centre study in the NHS has shown that $\mathrm{CFS} / \mathrm{ME}$ is a long term condition that persists for the majority of adult patients even after receiving specialist treatment. Whilst $50-65 \%$ experienced little or no change in their condition 1-5 years after accessing a specialist service and $10-20 \%$ reported a deterioration, up to $30 \%$ of patients reported very much or much better health (and the majority of those who experienced little or no change had improved slightly). Given the adverse impact of CFS/ME on patients and their families, substantial improvement in $20-30 \%$ of the approximately 8000 patients treated each year by specialist CFS/ ME services in England represents a large individual and societal benefit, and supports the argument that services need to be sufficiently resourced to treat promptly all newly diagnosed patients according to individual need.

\section{Additional files}

Additional file 1: Table S1. Characteristics of newly-referred patients with and without 12-month follow-up data across CFS/ME specialist services. Table S2. Treatments received by newly-referred patients across CFS/ME specialist services. Table S3. Mean change $(95 \% \mathrm{Cl})$ in patient-reported outcome measures between assessment and 1-year follow-up, categorised by overall improvement in health. Table S4. Baseline characteristics of former patients with and without 2- to 5-year follow-up data across CFS/ME specialist services. (DOCX 27 kb)
Additional file 2: Figure S1. Changes (mean difference with 95\% Cl) in patient reported measures between initial assessment and 1-year followup by overall improvement in health among patients treated by CFS/ME specialist services. (TIFF $12271 \mathrm{~kb}$ )

\section{Acknowledgements}

We thank the patients and clinical teams who participated in this study.

Funding

SC is funded by an NIHR Postdoctoral Fellowship (PDF-2013-06-011). EC is funded by an NIHR Senior Research Fellowship (SRF-2013-06-013).

\section{Availability of data and materials}

The data on which this study has been based are available from the University of Bristol Research Data Repository, http://data.bris.ac.uk/data under the DOI: 10.5523/bris.3nfgkcm2ce6eg28rt02u86murj

\section{Authors' contributions}

SC had the original idea for the study, and performed all data management and statistical analyses; EC provided supervision and clinical guidance; SC wrote the first draft and incorporated comments from EC; both authors contributed to the interpretation and writing of the paper, and read and approved the final manuscript.

Ethics approval and consent to participate

This study had NHS Research Ethics Committee approval (14/NW/0242), and all patients provided written informed consent.

\section{Consent for publication}

Not applicable.

\section{Competing interests}

EC is a medical advisor for the Sussex \& Kent ME/CFS Society.

\section{Publisher's Note}

Springer Nature remains neutral with regard to jurisdictional claims in published maps and institutional affiliations.

Received: 14 February 2017 Accepted: 6 July 2017

Published online: 14 July 2017

References

1. Collin SM, Nikolaus S, Heron J, Knoop H, White PD, Crawley E. Chronic fatigue syndrome (CFS) symptom-based phenotypes in two clinical cohorts of adult patients in the UK and The Netherlands. J Psychosom Res. 2016:81:14-23.

2. Nacul LC, Lacerda EM, Campion P, Pheby D, Drachler Mde L, Leite JC, Poland F, Howe A, Fayyaz S, Molokhia M. The functional status and well being of people with myalgic encephalomyelitis/chronic fatigue syndrome and their carers. BMC Public Health. 2011;11:402.

3. Sabes-Figuera R, McCrone P, Hurley M, King M, Donaldson AN, Ridsdale L. The hidden cost of chronic fatigue to patients and their families. BMC Health Serv Res. 2010;10:56.

4. Collin SM, Crawley E, May MT, Sterne JA, Hollingworth W. The impact of CFS/ME on employment and productivity in the UK: a cross-sectional study based on the CFS/ME national outcomes database. BMC Health Serv Res. 2011;11:217.

5. Johnston S, Brenu EW, Staines D, Marshall-Gradisnik S. The prevalence of chronic fatigue syndrome/myalgic encephalomyelitis: a meta-analysis. Clin Epidemiol. 2013;5:105-10.

6. Collin SM, Sterne JA, Hollingworth W, May MT, Crawley E: Equity of access to specialist chronic fatigue syndrome (CFS/ME) services in England (20082010): a national survey and cross-sectional study. BMJ Open. 2012;2(4).

7. Pinching AJ, Noons P. CFS/ME service investment Programme 2004-2006 Programme report. Plymouth: Peninsula Medical School; 2006.

8. National Institute for Health and Care Excellence (NICE). Chronic fatigue syndrome/myalgic encephalomyelitis (or encephalopathy): diagnosis and management of CFS/ME in adults and children (NICE guidelines CG53). London: NICE; 2007. 
9. Chalder T, Berelowitz G, Pawlikowska T, Watts L, Wessely S, Wright D, Wallace EP. Development of a fatigue scale. J Psychosom Res. 1993; 37(2):147-53.

10. Vercoulen JH, Swanink CM, Fennis JF, Galama JM, van der Meer JW, Bleijenberg G. Dimensional assessment of chronic fatigue syndrome. J Psychosom Res. 1994;38(5):383-92.

11. Ware JE Jr, Sherbourne CD. The MOS 36-item short-form health survey (SF-36). I. Conceptual framework and item selection. Med Care. 1992;30(6):473-83.

12. Mundt JC, Marks IM, Shear MK, Greist JH. The work and social adjustment scale: a simple measure of impairment in functioning. Br J Psychiatry. 2002;180:461-4

13. Snaith RP. The hospital anxiety and depression scale. Health Qual Life Outcomes. 2003;1:29.

14. Johns MW. A new method for measuring daytime sleepiness: the Epworth sleepiness scale. Sleep. 1991;14(6):540-5.

15. Jenkins CD, Stanton BA, Niemcryk SJ, Rose RM. A scale for the estimation of sleep problems in clinical research. J Clin Epidemiol. 1988;41(4):313-21.

16. Haywood KL, Staniszewska S, Chapman S. Quality and acceptability of patient-reported outcome measures used in chronic fatigue syndrome/ myalgic encephalomyelitis (CFS/ME): a systematic review. Qual Life Res. 2012;21(1):35-52.

17. Worm-Smeitink M, Nikolaus S, Goldsmith K, Wiborg J, Ali S, Knoop H, Chalder T. Cognitive behaviour therapy for chronic fatigue syndrome: differences in treatment outcome between a tertiary treatment centre in the United Kingdom and the Netherlands. J Psychosom Res. 2016:87:43-9.

18. White PD, Goldsmith KA, Johnson AL, Potts L, Walwyn R, DeCesare JC, Baber $\mathrm{HL}$, Burgess $\mathrm{M}$, Clark LV, Cox DL, et al. Comparison of adaptive pacing therapy, cognitive behaviour therapy, graded exercise therapy, and specialist medical care for chronic fatigue syndrome (PACE): a randomised trial. Lancet. 2011;377(9768):823-36.

19. Sharpe M, Goldsmith KA, Johnson AL, Chalder T, Walker J, White PD. Rehabilitative treatments for chronic fatigue syndrome: long-term follow-up from the PACE trial. Lancet Psychiatry. 2015;2(12):1067-74.

20. Crawley E, Collin SM, White PD, Rimes K, Sterne JA, May MT. Treatment outcome in adults with chronic fatigue syndrome: a prospective study in England based on the CFS/ME National Outcomes Database. QJM. 2013; 106(6):555-65.

21. McCrone $P$, Sharpe $M$, Chalder T, Knapp M, Johnson AL, Goldsmith KA White PD. Adaptive pacing, cognitive behaviour therapy, graded exercise, and specialist medical care for chronic fatigue syndrome: a costeffectiveness analysis. PLoS One. 2012;7(8):e40808.

22. Beasley M, Prescott GJ, Scotland G, McBeth J, Lovell K, Keeley P, Hannaford PC, Symmons DP, MacDonald RI, Woby S, et al. Patient-reported improvements in health are maintained 2 years after completing a short course of cognitive behaviour therapy, exercise or both treatments for chronic widespread pain: long-term results from the MUSICIAN randomised controlled trial. RMD Open. 2015;1(1):e000026.

23. Broughton J, Harris S, Beasant L, Crawley E, Collin SM. Adult patients' experiences of NHS specialist services for chronic fatique syndrome (CFS/ ME): a qualitative study in England. BMC Health Serv Res. 2017;17(1):384.

24. Picariello F, Ali S, Foubister C, Chalder T: 'It feels sometimes like my house has burnt down, but I can see the sky': A qualitative study exploring patients' views of cognitive behavioural therapy for chronic fatigue syndrome. Br J Health Psychol; 2017. doi:10.1111/bjhp.12235.

25. Murdock KW, Wang XS, Shi Q, Cleeland CS, Fagundes CP, Vernon SD. The utility of patient-reported outcome measures among patients with myalgic encephalomyelitis/chronic fatigue syndrome. Qual Life Res. 2017;26(4):913-21.

26. Cvejic E, Lloyd AR, Vollmer-Conna U. Neurocognitive improvements after best-practice intervention for chronic fatigue syndrome: preliminary evidence of divergence between objective indices and subjective perceptions. Compr Psychiatry. 2016;66:166-75.

27. McInnis OA, Matheson $K$, Anisman H. Living with the unexplained: coping, distress, and depression among women with chronic fatigue syndrome and/or fibromyalgia compared to an autoimmune disorder. Anxiety Stress Coping. 2014;27(6):601-18

28. Joustra ML, Janssens KA, Bultmann U, Rosmalen JG. Functional limitations in functional somatic syndromes and well-defined medical diseases. Results from the general population cohort LifeLines. J Psychosom Res. 2015;79(2):94-9.

29. Del Re AC, Fluckiger C, Horvath AO, Symonds D, Wampold BE. Therapist effects in the therapeutic alliance-outcome relationship: a restrictedmaximum likelihood meta-analysis. Clin Psychol Rev. 2012;32(7):642-9.
30. Goldberg SB, Hoyt WT, Nissen-Lie HA, Nielsen SL, Wampold BE. Unpacking the therapist effect: impact of treatment length differs for high- and lowperforming therapists. Psychother Res. 2016:1-13.

31. Heins MJ, Knoop H, Bleijenberg G. The role of the therapeutic relationship in cognitive behaviour therapy for chronic fatigue syndrome. Behav Res Ther. 2013;51(7):368-76.

\section{Submit your next manuscript to BioMed Central and we will help you at every step:}

- We accept pre-submission inquiries

- Our selector tool helps you to find the most relevant journal

- We provide round the clock customer support

- Convenient online submission

- Thorough peer review

- Inclusion in PubMed and all major indexing services

- Maximum visibility for your research

Submit your manuscript at www.biomedcentral.com/submit
Biomed Central 